\title{
SHOULD PATIENT SETUP IN LUNG CANCER BE BASED ON THE PRIMARY TUMOR? AN ANALYSIS OF TUMOR COVERAGE AND NORMAL TISSUE DOSE USING REPEATED POSITRON EMISSION TOMOGRAPHY/COMPUTED TOMOGRAPHY IMAGING
}

Citation for published version (APA):

van Elmpt, W., Ollers, M., Lambin, P., \& De Ruysscher, D. (2012). SHOULD PATIENT SETUP IN LUNG CANCER BE BASED ON THE PRIMARY TUMOR? AN ANALYSIS OF TUMOR COVERAGE AND NORMAL TISSUE DOSE USING REPEATED POSITRON EMISSION TOMOGRAPHY/COMPUTED TOMOGRAPHY IMAGING. International Journal of Radiation Oncology Biology Physics, 82(1), 379-385. https://doi.org/10.1016/j.ijrobp.2010.09.016

Document status and date:

Published: 01/01/2012

DOI:

10.1016/j.jijrobp.2010.09.016

Document Version:

Publisher's PDF, also known as Version of record

\section{Document license:}

Taverne

Please check the document version of this publication:

- A submitted manuscript is the version of the article upon submission and before peer-review. There can be important differences between the submitted version and the official published version of record. People interested in the research are advised to contact the author for the final version of the publication, or visit the DOI to the publisher's website.

- The final author version and the galley proof are versions of the publication after peer review.

- The final published version features the final layout of the paper including the volume, issue and page numbers.

Link to publication

\footnotetext{
General rights rights.

- You may freely distribute the URL identifying the publication in the public portal. please follow below link for the End User Agreement:

www.umlib.nl/taverne-license

Take down policy

If you believe that this document breaches copyright please contact us at:

repository@maastrichtuniversity.nl

providing details and we will investigate your claim.
}

Copyright and moral rights for the publications made accessible in the public portal are retained by the authors and/or other copyright owners and it is a condition of accessing publications that users recognise and abide by the legal requirements associated with these

- Users may download and print one copy of any publication from the public portal for the purpose of private study or research.

- You may not further distribute the material or use it for any profit-making activity or commercial gain

If the publication is distributed under the terms of Article $25 \mathrm{fa}$ of the Dutch Copyright Act, indicated by the "Taverne" license above,

Download date: 26 Apr. 2023 


\title{
SHOULD PATIENT SETUP IN LUNG CANCER BE BASED ON THE PRIMARY TUMOR? AN ANALYSIS OF TUMOR COVERAGE AND NORMAL TISSUE DOSE USING REPEATED POSITRON EMISSION TOMOGRAPHY/COMPUTED TOMOGRAPHY IMAGING
}

\author{
Wouter van Elmpt, Ph.D., Michel Öllers, Ph.D., PhilipPe Lambin, M.D., Ph.D., \\ ANd Dirk De Ruysscher, M.D., Ph.D. \\ Department of Radiation Oncology (MAASTRO), GROW—School for Oncology and Developmental Biology, Maastricht University \\ Medical Centre, Maastricht, The Netherlands
}

\begin{abstract}
Purpose: Evaluation of the dose distribution for lung cancer patients using a patient setup procedure based on the bony anatomy or the primary tumor.

Methods and materials: For 39 patients with non-small-cell lung cancer, the planning fluorodeoxyglucose positron emission tomography/computed tomography (FDG-PET/CT) scan was registered to a repeated FDG-PET/CT scan made in the second week of treatment. Two patient setup methods were analyzed based on the bony anatomy or the primary tumor. The original treatment plan was copied to the repeated scan, and target and normal tissue structures were delineated. Dose distributions were analyzed using dose-volume histograms for the primary tumor, lymph nodes, lungs, and spinal cord.

Results: One patient showed decreased dose coverage of the primary tumor caused by progressive disease and required replanning to achieve adequate coverage. For the other patients, the minimum dose to the primary tumor did not significantly deviate from the planned dose: $-0.2 \pm 1.7 \%(p=0.71)$ and $-0.1 \pm 1.7 \%(p=0.85)$ for the bony anatomy setup and the primary tumor setup, respectively. For patients $(n=31)$ with nodal involvement, $10 \%$ showed a decrease in minimum dose larger than $5 \%$ for the bony anatomy setup and $13 \%$ for the primary tumor setup. The mean lung dose exceeded the maximum allowed $20 \mathrm{~Gy}$ in $21 \%$ of the patients for the bony anatomy setup and in $13 \%$ for the primary tumor setup, whereas for the spinal cord this occurred in $10 \%$ and $13 \%$ of the patients, respectively.

Conclusions: In $10 \%$ and $13 \%$ of patients with nodal involvement, setup based on bony anatomy or primary tumor, respectively, led to important dose deviations in nodal target volumes. Overdosage of critical structures occurred in 10-20\% of the patients. In cases of progressive disease, repeated imaging revealed underdosage of the primary tumor. Development of practical ways for setup procedures based on repeated high-quality imaging of all tumor sites during radiotherapy should therefore be an important research focus. (c) 2012 Elsevier Inc.
\end{abstract}

Patient setup, Lung cancer, Mediastinal lymph nodes, Adaptive radiotherapy, Dose distribution, Repeated imaging.

\section{INTRODUCTION}

In lung cancer treatment, the radiotherapy dose has been increased in many dose-escalation studies and has been shown to improve both local control and overall survival at reasonable normal tissue toxicity levels $(1,2)$. Both the primary tumor and the involved mediastinal lymph nodes are treated in the same treatment plan (3). Changes in volume of the primary tumor during treatment and also baseline shifts have been described in many studies (4-10). A complicating factor for accurate irradiation is that changes in lymph node position and their volume are not related to corresponding changes in the primary tumor, which hampers the use of the primary tumor as a surrogate for the lymph nodes (11-13).

Fluorodeoxyglucose positron emission tomography/computed tomography (FDG-PET/CT) imaging combined with an intravenous contrast-enhanced CT scan has become the standard imaging technique in locally advanced lung cancer $(14,15)$.

In the past, volumetric imaging was restricted to a threedimensional (3D) planning (PET-)/CT scan made during the treatment planning procedure, but recent advances in
Reprint requests to: Wouter van Elmpt, Ph.D., Department of Radiation Oncology (MAASTRO Clinic), GROW-School for Oncology and Developmental Biology, Maastricht University Medical Centre, Dr. Tanslaan 12, NL-6229 ET Maastricht, The Netherlands. Tel: (+31) 88-44-55-666; Fax: (+31) 88-44-55-667; E-mail: wouter.vanelmpt@maastro.nl
Conflict of interest: none.

Acknowledgment-This study was performed within the framework of CTMM, the Center for Translational Molecular Medicine (www.ctmm.nl), project AIRFORCE number 030-103.

Received May 26, 2010, and in revised form Sept 24, 2010. Accepted for publication Sept 24, 2010. 
in-room imaging of predominantly kilovolt $(\mathrm{kV})$ and megavolt (MV) cone-beam CT have increased the use of patient alignment based on 3D image information (16). These new techniques give quantitative information on the volume and position of the primary tumor during treatment, but for imaging of the mediastinal lymph nodes they remain suboptimal. Hence, localization and quantification of the mediastinal lymph nodes is difficult in such cone-beam CT images.

These multiple target volumes (primary tumor and lymph nodes) thus result in many regions of interest that can be registered for deriving the actual patient setup. Patient setup by registering the bony anatomy is the current state of practice, but also registration of the primary tumor might yield better primary tumor coverage and reduced margins. However, if an integrated elective or involved mediastinal lymph node irradiation in a single treatment plan is used, a match based on the location of the primary tumor might act to the detriment of the dose coverage of these nodes. By contrast, a match of the bony anatomy might cause underdosage of the primary tumor if a baseline shift of the primary tumor occurs during treatment.

PET/CT imaging with intravenous contrast medium as the most optimal image modality to detect nodal involvement was selected before and during treatment. The dose is recalculated inside the repeated CT imaging data set that has all target and normal structures delineated, and an analysis is performed in terms of dose parameters and dose coverage of the primary tumor, involved mediastinal lymph nodes, and normal tissue. Such an analysis combines the dose distribution based on different patient setup strategies with possible changes in patient anatomy and tumor volume. The aim of this study was to investigate the accuracy of the treatment plan for a setup procedure based on the bony anatomy or the primary tumor for a large group of unselected patients.

\section{METHODS AND MATERIALS}

\section{Patient characteristics, image acquisition, and treatment}

Between June 2008 and December 2008, we prospectively imaged 39 lung cancer patients who received radical treatment in the second week during treatment. The protocol was approved by the Institutional Review Board, and all patients gave informed consent. Both small-cell lung cancer (SCLC) and non-small-cell lung cancer (NSCLC) patients were included. Patients scheduled for stereotactic body radiotherapy were excluded.

Four-dimensional (4D) respiration-correlated CT imaging was performed for all patients using our standard 4D respirationcorrelated CT imaging protocol together with a 3D FDG-PET image and a 3D CT scan using an intravenous iodine-based contrast medium (XENETIX 300, Guerbet, Aulnay-sous-Bois, France) (4). Imaging was performed on a dedicated PET/CT scanner (Siemens TruePoint Biograph 40, Siemens Molecular Imaging, Knoxville, TN). Patients were positioned in the radiotherapy position using a dedicated arm support. The patient's breathing was monitored using a pressure sensor in a belt strapped around the patient's chest (AZ-733 V, Anzai Medical Corporation, Tokyo, Japan). The following 4D CT scan parameters were used: $120 \mathrm{kV}$ tube voltage, $800 \mathrm{mAs}$, and $3 \mathrm{~mm}$ reconstructed slice thickness. The 4D CT was reconstructed in eight $\mathrm{CT}$ phases using an amplitude-based binning method. Injected activity (MBq) of FDG depended on the weight $(\mathrm{kg})$ of the patient and was equal to 4 times the body weight plus $20 \mathrm{MBq}$.

The gross tumor volume of the primary tumor (GTVprim) and involved mediastinal lymph nodes (GTVlymph) were delineated by the radiation oncologist. Expanding the GTVs with a margin of $5 \mathrm{~mm}$ resulted in the clinical target volumes (CTVprim and CTVlymph, respectively); the radiation oncologist was allowed to edit the CTV to exclude possible invasion into bony anatomy or blood vessels. The planning target volume of the primary tumor (PTVprim) was defined as the CTVprim with an additional margin of $10 \mathrm{~mm}$. For the PTV of the lymph nodes (PTVlymph) a CTV-toPTV margin of $5 \mathrm{~mm}$ was used.

The patients were treated according to our clinical protocol. On the 50\% exhale phase of the 4D CT scan, the target volumes and normal tissues were delineated and used for 3D conformal treatment planning using homogeneity constraints around the target volume of $90-115 \%$ of the prescribed dose.

For the SCLC, patients a dose of 45 Gy was delivered in 30 fractions (17). For the NSCLC patients, a dose-escalation protocol based on normal tissue constraints was used. Patients received no chemotherapy, induction, or concurrent chemotherapy with radiotherapy. For the NSCLC patients without chemotherapy or receiving sequential chemoradiotherapy, a maximum escalated dose up to $79.2 \mathrm{~Gy}$ in twice-daily fractions of $1.8 \mathrm{~Gy}$ was used, depending on normal tissue constraints $(2,18,19)$. For the patients receiving concurrent chemoradiotherapy, a dose escalation based on normal tissue toxicity up to $69 \mathrm{~Gy}$ was performed; first a fractionation scheme of 30 fractions of 1.5 Gy twice daily, and afterwards a dose escalation with fraction sizes of $2.0 \mathrm{~Gy}$ once daily was used.

\section{Repeated imaging during treatment and delineation}

Repeated imaging was performed in the second week of radiotherapy treatment. For this imaging session, the FDG-PET/CT scan was acquired using the same protocol as the planning CT scan, including the contrast-enhanced CT scan, with the patient positioned in radiotherapy position. On this repeated scan, the GTVs and CTVs were copied from the planning CT scan and afterwards manually adjusted by a radiation oncologist using the same target volume definition guidelines as used for the planning scan. The lungs and spinal cord were also delineated on these scans.

\section{Image registration procedure}

The CT scans of both time points were manually registered. This rigid registration allowed only translations to mimic the current widely used patient setup procedure during external beam radiotherapy treatment. Two independent persons performed these registrations based on either the bony anatomy or the primary tumor. For the bony anatomy registration, all the visible bony anatomy in the axial slices surrounding the primary tumor and involved mediastinal lymph nodes was used for the registration. For the tumor match, the GTV of the primary tumor was registered between the planning and the repeated CT scan. The average of the values for the translation vectors in the three orthogonal directions of the two observers was used to calculate the applied setup vector.

\section{Dose recalculation}

The dose distribution was recalculated using the CT scan of the repeated imaging session and applying the original treatment plan, including all monitor unit settings and beam parameters but with the isocenter derived from the patient setup procedure. The two dose distributions were calculated with the isocenter derived from 
Table. Patient characteristics

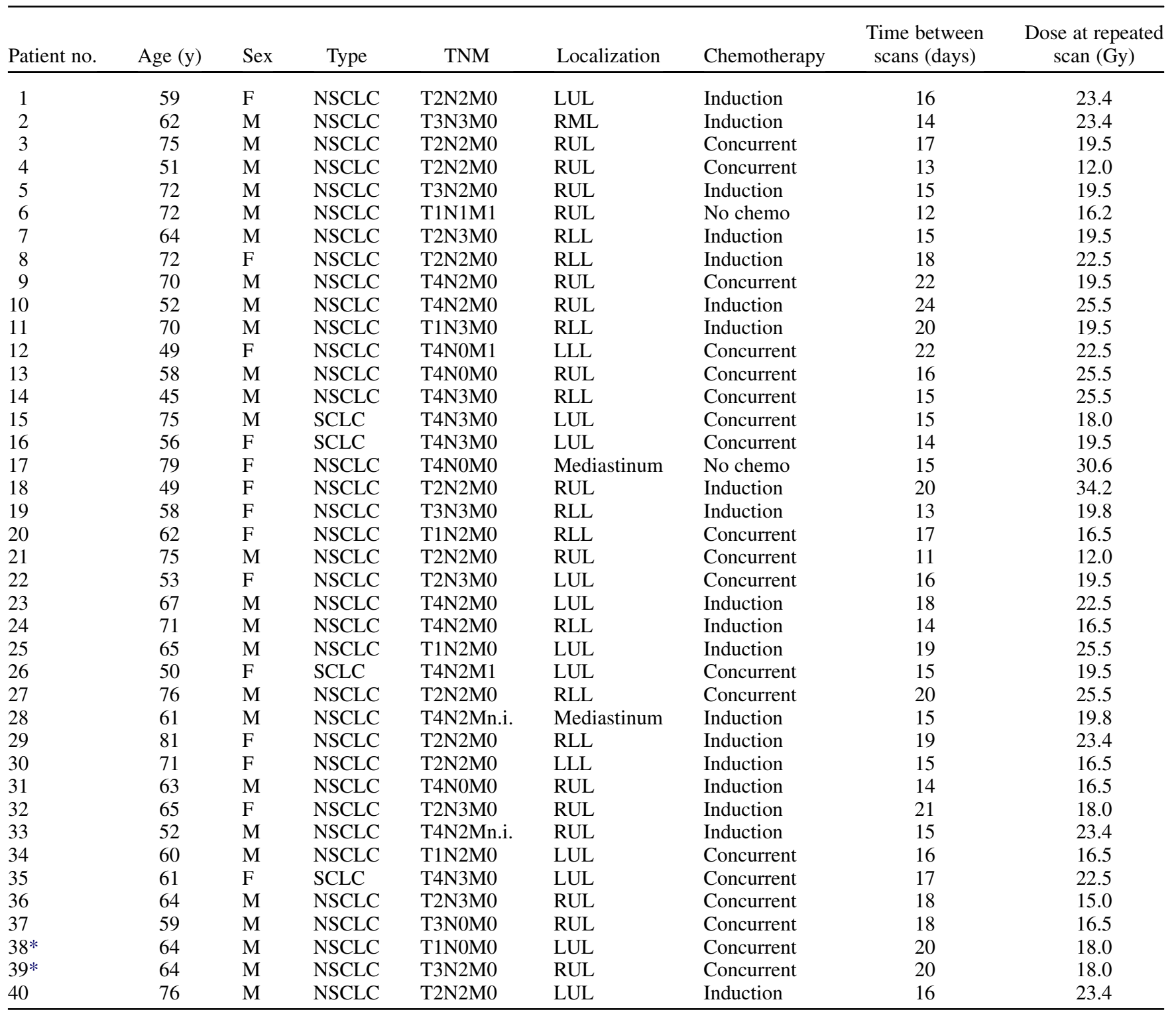

Abbreviations: $\mathrm{T}=$ tumor; $\mathrm{N}=$ nodes; $\mathrm{M}=$ metastases; $\mathrm{NSCLC}=$ non-small-cell lung cancer; $\mathrm{LUL}=$ left upper lobe; $\mathrm{RML}=$ right middle lobe; RUL = right upper lobe; RLL = right lower lobe.

* Patient 38 and 39 was a single patient with two primary tumors inside the lung; this patient was analyzed separately for each primary tumor.

the bony anatomy or the primary tumor registration. Dose distributions were recalculated using the same advanced superposition algorithm implemented in the treatment planning system (XiO 4.5.0, CMS, St. Louis, MO) as used for the treatment planning.

\section{Dose distribution analysis}

The dose distribution calculated on the repeated CT scan was compared to the planning CT scan by using dose-volume histogram parameters. For the target volumes, the CTV was taken as the structure of interest because the PTV concept is valid only during treatment planning to achieve adequate coverage of the CTV during treatment $(20,21)$. For both the CTVprim and the CTVlymph, the minimum dose to $99 \%$ of the volume of interest (D99\%), the mean dose, and the volume receiving $90 \%$ of the prescribed dose (V90\%) were calculated. For the normal tissues, the mean lung dose (MLD) was calculated based on the union of both lungs but with the GTVs excluded from the volume. The maximum dose to $0.1 \%$ of the spinal cord (D0.1\%) was also calculated.

\section{Statistical evaluation}

A Wilcoxon signed-rank test was used for testing of significance of paired results. Analyses were performed in SPSS (version 17.0, Chicago, IL). The results are presented as mean values \pm 1 standard deviation (SD) with the range also indicated, and $p$ values below 0.05 were assumed to be statistically significant.

\section{RESULTS}

\section{Patient characteristics}

The patient characteristics are shown in the table. In total, 39 patients were successfully imaged before radiotherapy and in the second week of radiotherapy, 4 patients with 
SCLC and 35 with NSCLC. For an additional 9 patients, the repeated scan was not available because of either technical or logistic issues. The average dose received up to the repeated PET/CT imaging was $20.5 \pm 4.5$ Gy (range, 1234.2 ) delivered in $13.0 \pm 2.6$ fractions (range, $8-19$ ). On average there were $16.8 \pm 3.0$ days (range, $11-24$ ) between the two imaging sessions, and the repeated scan was performed $8.5 \pm 1.8$ days (range, 6-13) after the start of radiotherapy. Eighteen patients were treated with concurrent chemoradiotherapy, 19 patients with sequential chemotherapy and radiotherapy, and 2 patients with radiation treatment only. One patient was treated for two primary tumors inside the lung; these primary tumors were analyzed separately for the bony anatomy and primary tumor registration. Thirtyone patients had nodal involvement, whereas 8 patients were treated only on the primary tumor because they did not have nodal involvement. One patient was excluded because of complete remission shown on the repeated scan.

\section{Dose coverage of the primary tumor}

For 38 out of 39 primary tumors, the coverage of the CTVprim was $100 \%$. For 1 patient $(2.5 \%, 1 / 39)$ there was a clear reduction in tumor coverage described by a V90\% of $93 \%$ and $94 \%$ for the bony anatomy and primary tumor match, respectively. This loss in tumor coverage was due to tumor growth in the cranial direction having an increase in GTV volume of $24 \%$ (from $46.4 \mathrm{~cm}^{3}$ to $57.6 \mathrm{~cm}^{3}$ ). Hence, the treatment fields did not cover the cranial part of the CTV. A coronal slice through the primary tumor is shown in Fig. 1.

The difference between the D99\% of the planned dose and the D99\% of the recalculated dose based on the bony anatomy match and the primary tumor match was small: on average $-2.0 \pm 11.2$ (range, $-69 \%$ to $+5 \%, p=0.530$ ) and $-1.7 \% \pm 10.6 \%$ (range, $-65 \%$ to $+5 \%, p=0.650$ ) (Fig. 2). Excluding the patient with tumor growth, these numbers were $-0.2 \pm 1.7 \%$ (range, $-6.4 \%$ to $+4.6 \%, p=$ 0.711 ) and $-0.1 \% \pm 1.7 \%$ (range, $-5.9 \%$ to $+4.6 \%, p=$ 0.850). The mean dose inside CTVprim was approximately equal for the bony anatomy and tumor setup procedures compared to the planned mean dose: $0.1 \pm 1.3 \%$ (range, $-2.9 \%$ to $+4.9 \%, p=0.738$ ) and $0.2 \pm 1.3 \%$ (range, $-2.1 \%$ to $+4.7 \%, p=0.989)$, respectively.

\section{Dose coverage of the lymph nodes}

Thirty-one out of 39 patients (79\%) had involved mediastinal lymph nodes that were irradiated in the same treatment plan as the primary tumor. The dose coverage (D99\%) of the lymph nodes CTVlymph was on average equal to the planned dose for both the bony anatomy and tumor setups: $-0.9 \pm 3.6 \%$ (range, $-10 \%$ to $+6 \%, p=0.421$ ) and -0.8 $\pm 4.1 \%$ (range, -12 to $+8 \%, p=0.499$ ), respectively. The number of patients with a loss in coverage (D99\%) larger than $5 \%$ was $10 \%(n=3)$ for the bony anatomy setup and $13 \%(n=4)$ for the primary tumor setup (Fig. 2). For 1 patient (3\%) the V90\% dropped below $99 \%$ for the bony anatomy setup. For 2 patients $(6 \%)$ the V90\% was lower than $99 \%$ if the primary tumor setup procedure was chosen, although in all cases the V90\% was still larger than $97 \%$. The mean dose to the CTVlymph did not differ significantly between the planning and setups based on bony anatomy ( $\mathrm{p}=$ $0.906)$ or primary tumor $(\mathrm{p}=0.860)$.

\section{Dose to the normal tissues}

The normal tissue constraint that was frequently the doselimiting factor was the MLD, which was escalated to a maximum dose of $19 \pm 1 \mathrm{~Gy}$. The average MLD during treatment planning was $16.2 \pm 3.8$ Gy (range, 5.9-19.8 Gy). The individual values of the MLD are shown in Fig. 3. The difference with the bony anatomy setup was $1.8 \pm$ $6.4 \%$ (range, -9 to $+25 \%, p=0.132$ ), and for the primary tumor setup the values were $1.7 \pm 5.8 \%$ (range, -8 to + $20 \%, p=0.225)$. The number of patients with an increase in MLD larger than $5 \%$ was $23 \%(n=9)$ and $15 \%(n=6)$ for the bony anatomy and primary tumor setups, respectively. Twenty-one percent (8/39) of the patients exceeded the maximum allowed normal tissue constraint of $20 \mathrm{~Gy}$ for the bony anatomy setup, compared to $13 \%$ (5/39) for the primary tumor setup. The MLD could be up to $22 \mathrm{~Gy}$ if the repeated anatomy persisted and the treatment plan was be used for the entire treatment. Four patients (10\%) had a reduction in MLD of more than 5\% for the bony anatomy setup and 2 patients (5\%) for the primary tumor setup.

For the spinal cord, the maximum allowed dose expressed as the maximum dose to $0.1 \%$ of the volume (D0.1\%) was 54 Gy. The maximum dose values are shown in Fig. 3, and the

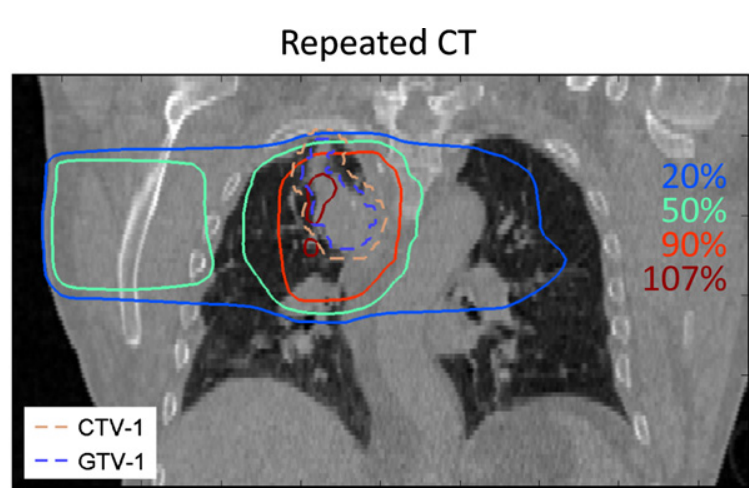

Fig. 1. Example of a patient who had tumor growth in the cranial direction. Coverage of this cranial part was not guaranteed by the original treatment plan and could not be adapted by a setup based on bony anatomy or tumor registration. $\mathrm{CT}=$ computed tomography. 

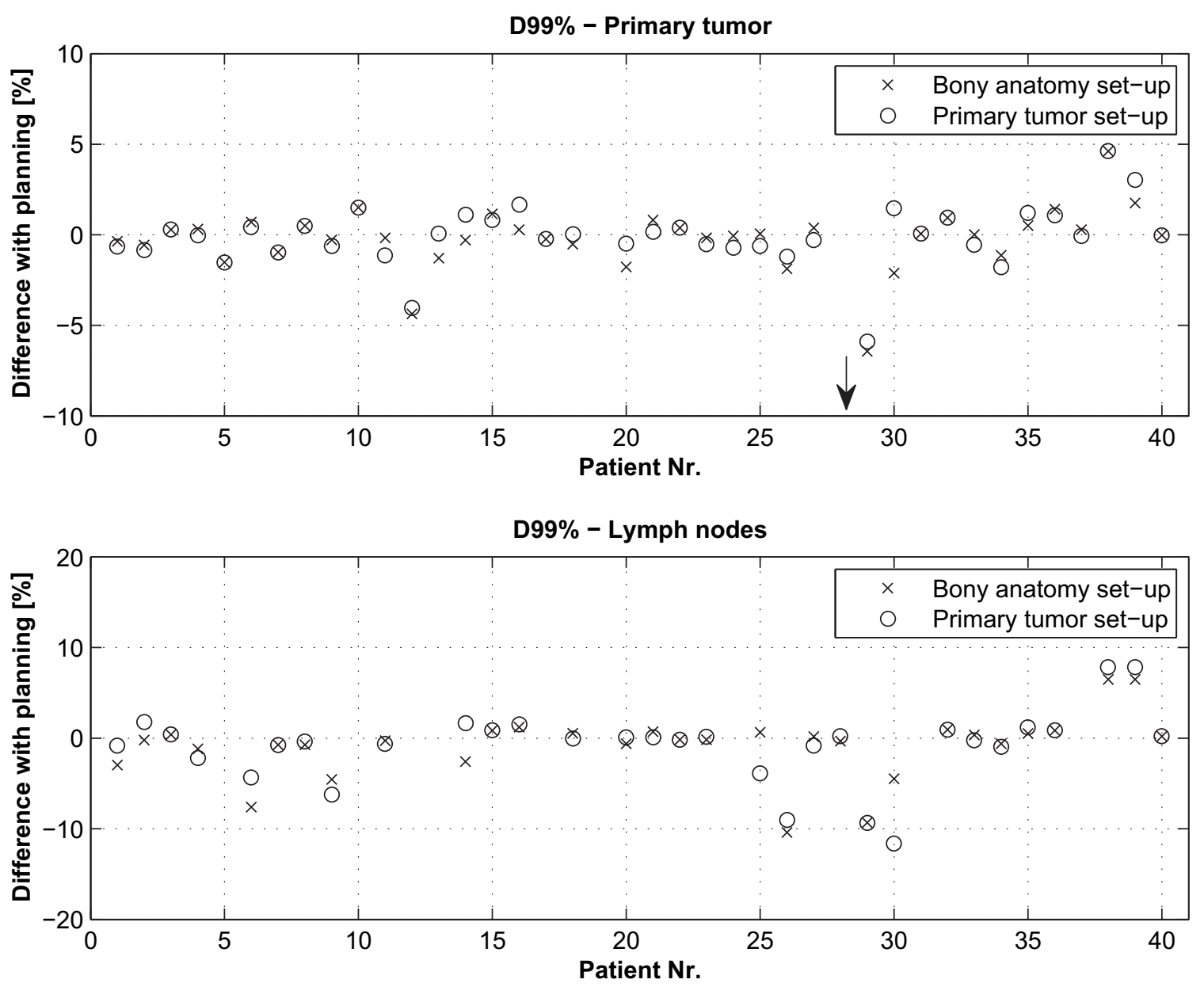

Fig. 2. Differences in minimum dose expressed as $99 \%$ of the volume of interest (D99\%) compared to the planning for the primary tumor (above) and lymph nodes (below) for patient setup based on the bony anatomy or primary tumor. Arrow indicates the large dose difference of the patient who had a growth of the primary tumor.

average maximum dose was $45.2 \pm 9.1$ Gy (range, 16.053.9 Gy). The differences between the bony anatomy set up and the primary tumor setup were $1.5 \pm 6.0 \%$ (range, $-8 \%$ to $+28 \%, p=0.402$ ) and $0.8 \pm 7.7 \%$ (range, $-22 \%$ to $+25 \% \%, p=0.606)$, respectively. The percentages of patients who received more than 54 Gy were $10 \%(n=4)$ for the bony anatomy setup and 13\% $(n=5)$ for the primary tumor setup.

\section{DISCUSSION}

We analyzed the patient setup based on two strategies: bony anatomy and primary tumor. For the primary tumor, there were no differences in the coverage (V90\%) of the CTV of the primary tumor for both methods. A single patient showed reduced coverage caused by tumor progression that could not be adequately tackled by either setup procedure. For this patient, replanning needed to be performed to take into account the larger primary tumor volume. For the involved lymph nodes, larger differences occurred, although the difference between the bony anatomy and tumor setups was slightly worse for the tumor-based setup: approximately $10 \%$ of the patients showed reduced minimum dose levels larger than 5\%. For the normal tissue dose, there was a similar trend visible: a small overall increase was observed of approximately $2 \%$, partly caused by the shrinkage of the primary tumor resulting in more lung volume that was irradiated. Compared to the bony anatomy setup, fewer patients exceeded the tolerance for the primary tumor setup, probably because the primary tumor setup focuses the beams in the same area as the planning, causing a minimum of high dose to the healthy lung around the primary tumor. For the spinal cord, the reverse occurs because the spinal cord is embedded in bony structures, causing fewer deviations for the bony anatomy setup compared to the spinal cord setup as expected.

Repeated imaging during treatment is thus necessary to assess possible dose deviations during treatment. The use of conventional CT imaging allows dose recalculation for the individual patient inside the treatment planning system and therefore assessment of the target coverage but also dose inside the normal tissues. We found that for a subgroup of patients this justified an adaptive treatment procedure. One patient had progressive disease that warranted replanning to achieve adequate coverage. Implementing an adaptive procedure to restore the coverage of the nodal target volume could improve $10-15 \%$ of the patient treatments; 

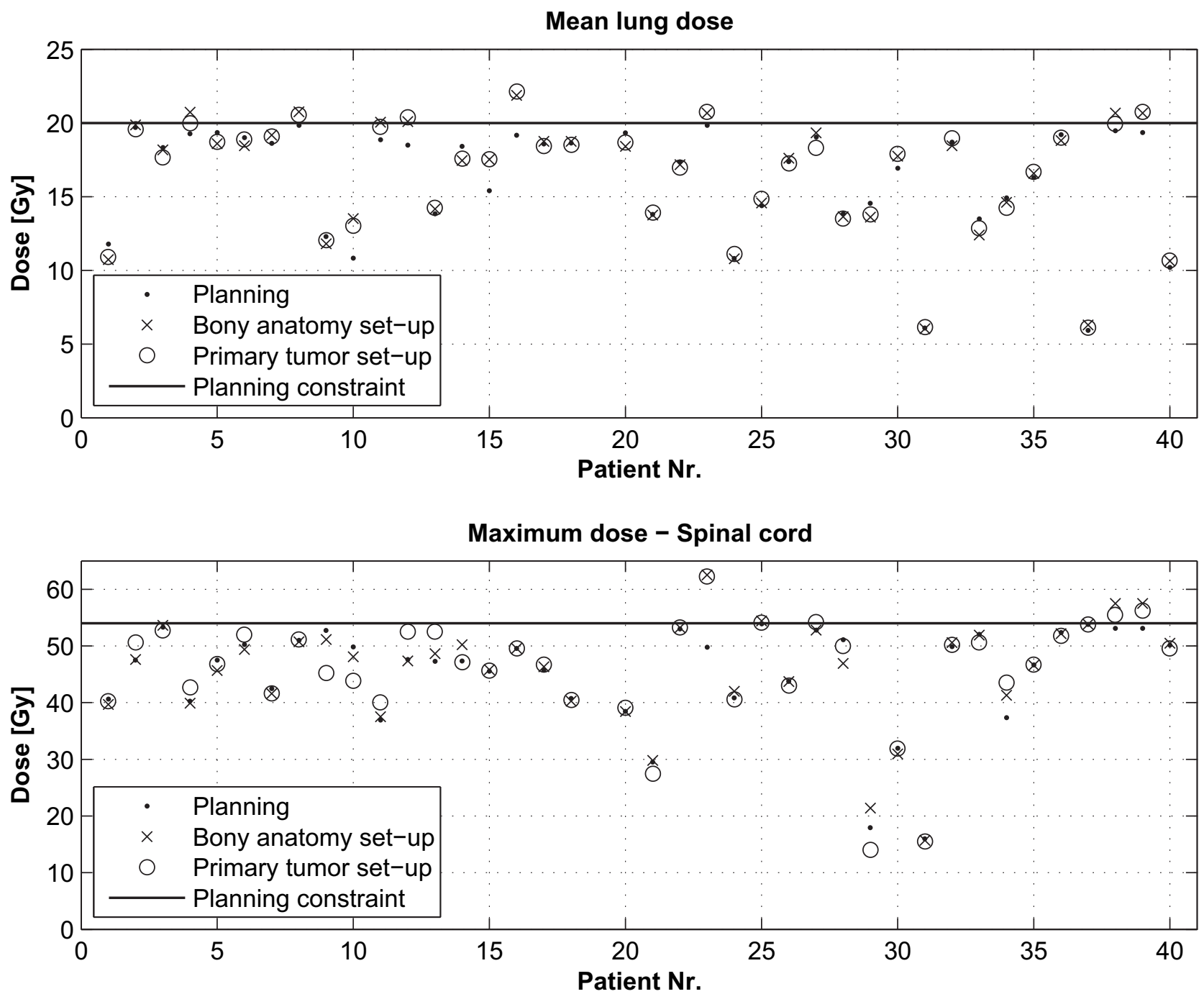

Fig. 3. Individual patient values for the mean lung dose (above) and maximum spinal cord dose (below) of the setup procedure based on the planned dose, bony anatomy, and primary tumor. The planning constraint is shown as a solid line.

however, practical ways of assessing nodal target structures need to be investigated. Deformable image registration methods might be a possibility for this (22). The currently used dose-escalation protocols based on normal tissues push to the target dose up to critical values for normal tissue toxicity, and repeated dose calculations show that planning constraints for the normal tissues may be exceeded during treatment for up to $20 \%$ of patients. If nonacceptable normal tissue doses are observed in individual patients, adaptation of the treatment plan may prevent serious toxicities.

In the present study, we used FDG-PET/CT imaging with contrast-enhanced CT because we believe this is at present the best way to perform target delineation for lung cancer patients that includes delineation of the involved mediastinal lymph nodes. With the use of non-contrast-enhanced CT or cone-beam CT alone, imaging of the mediastinal nodes is less reliable. The imaging technique during treatment should provide us with image information comparable to that seen on the planning CT scan. Therefore, we used the midventilation phase extracted from the 4D CT scan as the preferred imaging technique to be compared to the planning
4D CT scan. The use of 3D CT either in the planning phase or during treatment might introduce additional errors because the tumor might be captured in one of the extreme positions that are not representative for the actual treatment. Obviously, new techniques such as contrast-enhanced cone-beam CT imaging (23) or integrated magnetic resonance imaging with a linear accelerator (24) might be options to be explored.

Previous studies have shown that surrogates for time trends in nodal volume or baseline shifts are difficult, if not impossible, to obtain from primary tumor characteristics (9, 11-13). Hence, one has to be careful in adapting a treatment of the nodal volumes based on primary tumor characteristics. We therefore investigated in this study the influence of the patient setup procedure. On average, only moderate differences were observed for the lymph nodes, partly explained by the fact that the treatment plans were 3D conformal. Intensity-modulated radiotherapy treatment techniques, which are currently being used more and more, allow for even more conformal dose distributions to the target volumes, with the consequence that a shift of the 
dose distribution might have more impact on the coverage compared to the less conformal 3D dose distributions.

Based on the results of this study it was shown that choosing either a primary tumor setup method or a bony anatomy setup is not suitable for every individual patient. High-quality repeated imaging needs to be performed during treatment to assess the impact of dosimetric changes during treatment. We are currently implementing a protocol for all our lung cancer patients receiving radical treatment to obtain a second FDG-PET/CT scan during treatment to guarantee accuracy of treatment and if necessary adapt the treatment plan to reach the intended dose coverage of target volumes and prevent overdosage of the normal tissues.

\section{CONCLUSION}

Repeated imaging during treatment is useful to detect tumor progression that may lead to reduced target coverage. In $10-13 \%$ of the patients who had nodal involvement, setup based on bony anatomy or primary tumor led to important dose deviations in the involved lymph nodes, respectively. Setup procedures based on bony anatomy or primary tumor therefore do not guarantee correct dose delivery to the involved lymph nodes for all patients. The development of practical ways for repeated imaging of all tumor sites during radiotherapy should therefore be an important research focus.

\section{REFERENCES}

1. Belderbos JS, Heemsbergen WD, De Jaeger K, et al. Final results of a Phase I/II dose escalation trial in non-small-cell lung cancer using three-dimensional conformal radiotherapy. Int J Radiat Oncol Biol Phys 2006;66:126-134.

2. van Baardwijk A, Wanders S, Boersma L, et al. Mature results of an individualized radiation dose prescription study based on normal tissue constraints in stages I to III non-small-cell lung cancer. J Clin Oncol 2010;28:1380-1386.

3. De Ruysscher D, Wanders S, van Haren E, et al. Selective mediastinal node irradiation based on FDG-PET scan data in patients with non-small-cell lung cancer: A prospective clinical study. Int J Radiat Oncol Biol Phys 2005;62:988-994.

4. Bosmans G, van Baardwijk A, Dekker A, et al. Intra-patient variability of tumor volume and tumor motion during conventionally fractionated radiotherapy for locally advanced nonsmall-cell lung cancer: A prospective clinical study. Int $J$ Radiat Oncol Biol Phys 2006;66:748-753.

5. Fox J, Ford E, Redmond K, et al. Quantification of tumor volume changes during radiotherapy for non-small-cell lung cancer. Int J Radiat Oncol Biol Phys 2009;74:341-348.

6. Kupelian PA, Ramsey C, Meeks SL, et al. Serial megavoltage CT imaging during external beam radiotherapy for nonsmall-cell lung cancer: Observations on tumor regression during treatment. Int J Radiat Oncol Biol Phys 2005;63: 1024-1028.

7. Siker ML, Tome WA, Mehta MP. Tumor volume changes on serial imaging with megavoltage CT for non-small-cell lung cancer during intensity-modulated radiotherapy: How reliable, consistent, and meaningful is the effect? Int J Radiat Oncol Biol Phys 2006;66:135-141.

8. Chang J, Mageras GS, Yorke E, et al. Observation of interfractional variations in lung tumor position using respiratory gated and ungated megavoltage cone-beam computed tomography. Int J Radiat Oncol Biol Phys 2007;67:1548-1558.

9. Sonke JJ, Lebesque J, van Herk M. Variability of fourdimensional computed tomography patient models. Int $\mathrm{J} \mathrm{Ra}$ diat Oncol Biol Phys 2008;70:590-598.

10. Underberg RW, Lagerwaard FJ, van Tinteren H, et al. Time trends in target volumes for stage I non-small-cell lung cancer after stereotactic radiotherapy. Int J Radiat Oncol Biol Phys 2006;64:1221-1228.

11. Pantarotto JR, Piet AH, Vincent A, et al. Motion analysis of 100 mediastinal lymph nodes: Potential pitfalls in treatment planning and adaptive strategies. Int J Radiat Oncol Biol Phys 2009;74:1092-1099.

12. Bosmans G, van Baardwijk A, Dekker A, et al. Time trends in nodal volumes and motion during radiotherapy for patients with stage III non-small-cell lung cancer. Int J Radiat Oncol Biol Phys 2008;71:139-144.

13. van Elmpt W, Öllers M, van Herwijnen H, et al. Volume or position changes of the primary lung tumor during (chemo-)radiotherapy cannot be used as a surrogate for the mediastinal lymph node changes: The case for optimal mediastinal lymph node imaging during radiotherapy. Int J Radiat Oncol Biol Phys 2010.

14. Steenbakkers RJ, Duppen JC, Fitton I, et al. Reduction of observer variation using matched CT-PET for lung cancer delineation: A three-dimensional analysis. Int J Radiat Oncol Biol Phys 2006;64:435-448.

15. van Baardwijk A, Bosmans G, Boersma L, et al. PET-CT-based auto-contouring in non-small-cell lung cancer correlates with pathology and reduces interobserver variability in the delineation of the primary tumor and involved nodal volumes. Int $J$ Radiat Oncol Biol Phys 2007;68:771-778.

16. van Herk M. Different styles of image-guided radiotherapy. Semin Radiat Oncol 2007;17:258-267.

17. van Loon J, De Ruysscher D, Wanders R, et al. Selective nodal irradiation on basis of (18)FDG-PET scans in limited-disease small-cell lung cancer: A prospective study. Int J Radiat Oncol Biol Phys 2010;77:319-336.

18. van Baardwijk A, Bosmans G, Bentzen SM, et al. Radiation dose prescription for non-small-cell lung cancer according to normal tissue dose constraints: An in silico clinical trial. Int $J$ Radiat Oncol Biol Phys 2008;71:1103-1110.

19. van Baardwijk A, Bosmans G, Boersma L, et al. Individualized radical radiotherapy of non-small-cell lung cancer based on normal tissue dose constraints: A feasibility study. Int J Radiat Oncol Biol Phys 2008;71:1394-1401.

20. Stroom JC, de Boer HC, Huizenga H, et al. Inclusion of geometrical uncertainties in radiotherapy treatment planning by means of coverage probability. Int J Radiat Oncol Biol Phys 1999;43:905-919.

21. van Herk M, Remeijer P, Rasch C, et al. The probability of correct target dosage: dose-population histograms for deriving treatment margins in radiotherapy. Int J Radiat Oncol Biol Phys 2000;47:1121-1135.

22. Sonke JJ, Belderbos J. Adaptive radiotherapy for lung cancer. Semin Radiat Oncol 2010;20:94-106.

23. Tse RV, Moseley DJ, Siewerdsen J, et al. Intrahepatic tumor and vessel identification in intravenous contrast enhanced liver $\mathrm{kV}$ cone beam CT. Int J Radiat Oncol Biol Phys 2007;69:S666S667.

24. Lagendijk JJ, Raaymakers BW, Raaijmakers AJ, et al. MRI/ linac integration. Radiother Oncol 2008;86:25-29. 